\title{
O projeto americanista, a campanha pelo ferro e petróleo nas missivas de Monteiro Lobato e Arthur Neiva (1927-1942)
}

\author{
The americanist project, the campaign for iron and oil in the missions of \\ Monteiro Lobato and Arthur Neiva (1927-1942)
}

\author{
Rhaiane das Graças Mendonça Leal \\ Doutoranda do Programa de Pós-Graduação em História das \\ Ciências e da Saúde da Casa de Oswaldo Cruz. \\ rhaiane.leal@aluno.fiocruz.br
}

\begin{abstract}
Resumo: Este artigo propõe a pensar as temáticas das correspondências trocadas entre o literato Monteiro Lobato e o cientista Arthur Neiva, entre 1927 e 1942. O objetivo é compreender os diálogos entre os referidos intelectuais acerca da aplicação do projeto americanista, do desenvolvimento da metalurgia e da campanha do petróleo no Brasil. A metodologia empregada se deu por intermédio da análise dos arquivos do Centro de Pesquisa e Documentação de História Contemporânea no Brasil (CPDOC/ FGV). A questão nacional é apresentada nos projetos e concepções escritas em missivas de Lobato e Neiva, bem como as formas de engajamento com os debates intelectuais do período, e o repertório acionado para transformar o país em uma nação viável.
\end{abstract}

Palavras-chave: Monteiro Lobato, Arthur Neiva, Intelectuais.

\begin{abstract}
: his article proposes to think about the themes of the correspondence exchanged between the literate Monteiro Lobato and the scientist Arthur Neiva, between 1927 and 1942. The objective is to understand the dialogues between intellectuals about the application of the americanist project, the development of metallurgy and the oil campaign in Brazil. The methodology used was through the analysis of the archives of the Center for Research and Documentation of Contemporary History in Brazil (CPDOC/FGV). The national question is presented in the projects and conceptions written in letters by Lobato and Neiva, as well as the forms of engagement with the intellectual debates of the period, and the repertoire used to transform the country into a viable nation.
\end{abstract}

Keywords: Monteiro Lobato, Arthur Neiva, Intellectuals.

Este artigo é oriundo da dissertação "Nacionalismo militante: uma análise da correspondência de Monteiro Lobato e Arthur Neiva (1918-1942)" defendida no Programa de Pós-Graduação em História das Ciências e da Saúde. A pesquisa abordou a carreira dos intelectuais Monteiro Lobato (1882- 1948) e Arthur Neiva (1880-1942) entrelaçada aos temas das correspondências, estas depositadas no fundo pessoal ${ }^{1}$ de

\footnotetext{
${ }^{1}$ Fontes: Centro de Pesquisa e Documentação de História Contemporânea no Brasil - CPDOC/ FGV. Arquivo Arthur Neiva. Correspondência entre Arthur Neiva e Monteiro Lobato. Localização: AN c
} 
Arthur Neiva no Centro de Pesquisa e Documentação de História Contemporânea (CPDOC). A relação de amizade dos missivistas por três décadas perpassou os projetos nacionais e individuais. Dessa forma, o recorte deste estudo são os aspectos econômicos e políticos das cartas enviadas entre 1927 e 1942, com ênfase nas questões do americanismo, metalurgia e a campanha do petróleo no Brasil.

Ainda que pouco analisada a sua trajetória intelectual, o médico, cientista e político baiano. Arthur Neiva desenvolveu seu itinerário profissional especialmente nos estados do Rio de Janeiro e São Paulo, num momento de estruturação das políticas públicas em saúde e de campanhas sanitárias; de criação e consolidação de instituições de pesquisa científica. Período de forte engajamento dos intelectuais nos projetos relacionados à construção simbólica e material da nação brasileira (ENGEL, 2012). Ele iniciou a carreira na Inspetoria de Profilaxia de Febre Amarela ao lado de Oswaldo Cruz, e, posteriormente em 1906, ingressou no Instituto Oswaldo Cruz na área de entomologia. O seu trabalho mais conhecido foi ao lado de Belisário Penna na expedição científica pelo interior nos estados do norte e nordeste do Brasil (SÁ, 2009).

Em São Paulo, Arthur Neiva trabalhou no Serviço Sanitário e instalou medidas higiênicas rurais. No dia 2 de dezembro de 1917, inaugurou na cidade de Iguape o primeiro posto sanitário, onde simultaneamente se fez a profilaxia contra a malária e a ancilostomíase. Foi durante este trabalho que Monteiro Lobato conheceu o cientista Arthur Neiva. O início da escrita das cartas dos intelectuais começou em 21 de junho de 1918, ano este bastante significativo para a carreira dos missivistas, pois foi marcado por eventos que envolveram a participação de ambos intelectuais em projetos coletivos concernentes ao debate nacional (ENGEL, 2012; HOCHMAN, LIMA, 2000).

O cientista defendia o empenho conjuntamente a todos os esforços para convencer os poderes públicos da necessidade de sanear a nação (CASTRO SANTOS, 1985; BENCHIMOL, TEIXEIRA, 1993; HOCHMAN, LIMA, 2000; HOCHMAN, 2005; SÁ, 2009). Entre os anos de 1924 e 1927, Arthur Neiva dirigiu a Comissão de Estudos e Debelação da Praga Cafeeira do Estado de São Paulo (SILVA, 2006), em trabalho com Ângelo Moreira da Costa Lima e Edmundo Navarro de Andrade. Em 1928, o governo paulista o contratou como diretor para o Instituto Biológico de Defesa Agrícola e Animal. Durante a década de 1930, Arthur Neiva foi secretário de educação do governo de São Paulo, interventor federal da Bahia e deputado federal pelo Partido Social Democrático.

1918.06.21. Série: c - Correspondência / Data de produção: 21/06/1918 a 02/10/1942. Quantidade de documentos: 143 (227 folhas). 
José Bento Monteiro Lobato iniciou a sua carreira como promotor público na cidade de Areias, em São Paulo. Como jovem literato escreveu para jornais e revistas, com destaque para o jornal O Estado de São Paulo. O seu primeiro livro de sucesso foi “Urupês” em 1918, período em que foi editor-escritor e proprietário da Revista do Brasil. Fundou a empresa "Monteiro Lobato \& Cia", e a "Gráfico-Editora Monteiro Lobato". Ele ficou conhecido pelo gênero conto, e posteriormente consagrado como o grande escritor de obras infantis no Brasil. Neste artigo nos aprofundaremos no contexto da década de 1930, após o retorno dos Estados Unidos, Monteiro Lobato se engajou na questão do petróleo ao fundar a Companhia Nacional do Petróleo em 1931. A partir de então, o literato manifestou de forma polêmica e enfática as suas opiniões e convicções na imprensa e em sua produção intelectual.

Os missivistas deste estudo são de uma geração de intelectuais "polígrafos" (LUCA, 1999), iniciaram a atuação num momento que se estabeleciam as fronteiras da especialização intelectual no Brasil (SÁ, 2006). A produção literária e científica é integrada à história intelectual da Primeira República, visto isso na produção de periódicos especializados, as revistas de ciências e letras, as maganizes e as fontes impressas de cunho popular como os almanaques. Nesse sentido, as proposições de Sá (2006) estão em diálogo com a narrativa do trabalho científico de Arthur Neiva nas correspondências trocadas com Monteiro Lobato.

Arthur Neiva e Monteiro Lobato se aproximam no período da Primeira República, num cenário em que os intelectuais dependiam fundamentalmente das redes de sociabilidade familiares e pessoais, a fim de intermediarem suas conexões e atuação como suportes políticos e sociais (MICELI, 2001; HOCHMAN, 1993, 2005). A partir de 1930, os intelectuais tornaram-se atores mais próximos do Estado brasileiro, pois passaram a atuar em diversos setores do aparelho de Estado e também fora de suas instâncias. Esta intelectualidade por via de um projeto arbitrário de identidade nacional estabeleceu a valorização do trabalho à noção de cidadania.

O gênero epistolar é uma fonte que acumula temas e informações, estabelecendo uma narrativa plena de imagens e movimentos exteriores e interiores dos missivistas, assim como os espaços de sociabilidade (GOMES, 2004; SIRINELLI, 2003). Na virada da década de 1920 para 1930, Monteiro Lobato e Arthur Neiva se engajaram em diferentes funções em projetos. Observa-se a ampliação dos contatos profissionais dos intelectuais, na medida em que esses "homens de ação" expandiram seus ideais e negócios, com consequente formação de novas redes de sociabilidade. Os missivistas 
tiveram contato com personalidades de diferentes graus de projeção e importância política.

\section{O sonho americano lobatiano nas cartas enviadas a Arthur Neiva}

Em 1927, Monteiro Lobato foi nomeado Adido Comercial nos Estados Unidos pelo presidente Washington Luís, embarcando no navio American Legion com destino a Nova Iorque, onde assumiu o cargo e permaneceu até 1931 (IBAÑEZ; RONCON; ALVAES, 2012). Nesse período, Monteiro Lobato se associou a Fortunato Bulcão, diretor do Banco do Brasil e da Associação Comercial do Rio de Janeiro, a fim de conseguir apoio do governo e da iniciativa privada para implantar no Brasil o processo siderúrgico criado por William Smith. ${ }^{2}$

É um período em que Monteiro Lobato reverbera fortes críticas à burocracia estatal. A ineficiência do serviço público é um desses disfarces do patrimonialismo, chamado por Lobato de "parasitismo camuflado" (LEAL, 2020). A aversão ao funcionalismo público tanto por Lobato quanto por Neiva tem forte relação às críticas contundentes ao federalismo (VISCARDI, 2012), uma vez que eles se opunham ao modelo de liberalismo brasileiro tal como vigorara na Primeira República. O sonho americano de Lobato consiste em se identificar com um país de suposta "cultura" avançada, de espírito jovem, em contraposição à Europa. ${ }^{3}$

Na virada da década de 1920 para a de 1930, os projetos de Monteiro Lobato e Arthur Neiva ganharam outro formato - o literato não é apenas um editor e redator, tampouco Neiva o viajante da expedição científica de 1912 e prócere do sanitarismo. Os missivistas têm contato com personalidades de diferentes graus de projeção e importância política, de Getúlio Vargas até o perfurador do poço, passando por Armando de Sales Oliveira, engenheiro e político brasileiro, fundador da USP (LEAL, 2020). Dessa forma, uma rede de sociabilidade foi sendo construída a partir da literatura, da ciência e da

\footnotetext{
2 Willian C. Smith trabalhou no centro de siderurgia da Ford Motors, lecionava e pesquisava na Universidade de Detroit, era dono de uma empresa de consultoria para empresas siderúrgicas (IBAÑEZ; RONCON; ALVAES, 2012: 243). O Mr. Smith o marco inicial para o engajamento de Monteiro Lobato no setor da indústria siderúrgica. $\mathrm{O}$ famoso engenheiro citado nas correspondências e livros trabalhava para a Ford e patenteou uma nova forma de produzir ferro, o qual Monteiro Lobato chamou de Processo Smith nas correspondências trocadas com Neiva.

${ }^{3}$ Em carta Monteiro Lobato sugere a Arthur Neiva que o seu filho se americanize nos costumes e se torne um homem moderno segundo o perfil do "American Way of Life": "Terra de mocidade, onde até o Rockfeller e o Ford são perfeitamente moços, quem nasceu moço encontra aqui a sua verdadeira pátria mental e moral." Carta de Neiva a Lobato em 10 de abril de 1928. Fundo Arthur Neiva/ AN 18/06/1921.
} 
atuação em favor de projetos institucionais, políticos e sociais.

O engajamento de Monteiro Lobato com o desenvolvimento econômico o motivou a montar uma equipe de sócios para viabilizar as negociações entre o Estado e a Cia Siderúrgica, revelando aos representantes de confiança os segredos da empreitada com William Smith. São eles: "Sampaio Correia, Victor Konder, ambos também envolvidos no Movimento Tenentista do Rio de Janeiro; Edmundo Navarro de Andrade e Macedo Soares (ex-presidente da Associação Comercial de São Paulo e um dos envolvidos no movimento Tenentista de 1924) e Paulo Prado, escritor e ex-editor da Revista do Brasil em São Paulo” (NUNES, 1981: 26). Em sua análise, a siderurgia significava a primeira indústria legítima a se estabelecer no Brasil, sem tarifas de favores oficiais, o ferro seria a base de tudo:

Todos os nossos problemas, até os morais, são uma consequência da nossa inominável miséria, e essa miséria veio porque não tínhamos ferro. Só se criam riquezas, só dão origem a civilizações os países que têm ferro e carvão - Inglaterra, Alemanha, E. Unidos. Os que não possuem esses elementos ficaram a funcionar de satélites, sempre dependentes e pobres. Nós tínhamos ferro e tão mais carvão que equivalia e não tê-lo. E por isso tivemos de marcar passo até agora. Não preciso me estender nisto, dirigindo-me uma inteligência como a sua. O sr. sabe que o ferro é base de tudo (Carta de Lobato a Neiva em New York, 3 de maio de 1928. Fundo Arthur Neiva/ AN 18/06/1921).

Cabe ressaltar que Monteiro Lobato escreve em período onde a produção cafeeira era o esteio da economia brasileira na década de 1920, contribuindo com 70 por cento das exportações brasileiras. O estado de São Paulo era o maior produtor do país, controlava quase a metade do comércio cafeeiro mundial (LOVE, 1982). Nesse cenário, em 1924 foi criado o Instituto do Café (Carta de Lobato enviada a Neiva em 10/04/1928. Fundo Arthur Neiva/ AN 18/06/1921) e, dois anos depois, o Banco do Estado de São Paulo, cuja principal finalidade era fornecer crédito agrícola com base nos estoques (SILVA, 2006). Recrudesceu o círculo vicioso, nos quais bons preços estimulavam novas plantações, e em seguida, superprodução. Em relação à economia agrária nacional, vale ressaltar que o jornal O Estado de São Paulo é caracterizado como órgão professor do liberalismo da burguesia cafeeira paulista nos anos 1920, voltado para um público mais elitizado (FERREIRA, 2000). Envolvido com a modernização da agricultura e com a promoção 
das ciências enquanto impulsionadoras do progresso, O Estado de São Paulo identificouse estreitamente com os interesses dos lavradores agremiados na Sociedade Rural Brasileira (SRB), da qual fez parte seu presidente, Júlio de Mesquita Filho ${ }^{4}$

A crise de 1929 abateu profundamente a lavoura e marcou de forma decisiva o destino da burguesia cafeeira nos anos de 1930. Monteiro Lobato sofreu as consequências financeiras do crash da bolsa de valores, no qual investira todos os seus recursos, e obrigado a se desfazer de suas ações da Companhia Editora Nacional. Não por acaso Monteiro Lobato enviou um relatório ao ministro das Relações Exteriores, Otávio Mangabeira, sugerindo, entre várias outras medidas, que o governo brasileiro reconsiderasse os altos impostos de exportação e que, com urgência, investisse em propaganda (LEAL, 2020: 124).

Em 1928, por solicitação do Itamaraty, Lobato enviou um minucioso balanço sobre o comércio Brasil-Estados Unidos. Dentre os informes, relatórios e sugestões que fez ao longo do ano, destaca-se seu interesse por combustíveis alternativos, em particular, o coco de babaçu, que substituiria o carvão hulha na obtenção de gusa no Processo Smith. Monteiro Lobato pretendia substituir o carvão por coco de babaçu, cuja polpa era extraída de forma artesanal (LEAL, 2020; IBAÑEZ; ALVEZ; RONCON, 2012).

No final do ano de 1928, Monteiro Lobato já previa a situação do mercado de exportação internacional, e elogiou Neiva por investir na produção de laranjas em sociedade com Edmundo Navarro: "Parabéns pela sociedade com o Navarro nas laranjas. Vão fazer um excelente negócio"5. Na carta de 5 de abril de 1929, Monteiro Lobato sugere a substituição do café por exportações de laranja, parabenizando novamente Arthur Neiva por essa iniciativa. Monteiro Lobato mencionou o risco de o Brasil perder o monopólio do café, e critica o fato desse ser o principal motor da economia. Considerava que o investimento em laranjas possa ser o caminho para superar a crise que se aproximava no Brasil:

Meus parabéns pelas laranjas. O café me parece em perigo e quem pensar e antecipar-se no cultivo de alguma das coisas que tem de substituir dará tacada. Acho a nossa situação econômica muito perigosa. Tenho diante dos olhos um gráfico da nossa exportação que figura um perfeito L., a linha vertical formada

\footnotetext{
${ }^{4}$ Júlio de Mesquita era um importante nome da rede de sociabilidade intelectual de Monteiro Lobato e Arthur Neiva, fundador da Revista do Brasil e esteve à frente da Revolução Constitucionalista de 1932.

${ }^{5}$ Smith trabalhou como gerente-geral numa siderúrgica de Buffalo em Nova Iorque, empresa produtora de bicicletas e fornecedora de equipamentos para a empresa de Ford.
} 
pelo café a linha horizontal pelos outros produtos [...]. Qualquer crise nessa perna porá abaixo o bicho e a crise se aproxima. A política de preços altos do Instituto é ótima no momento, mas está fazendo e fará o Brasil perder o monopólio que tem desse produto, com o desenvolvimento do café em outros países (Carta de Lobato a Neiva em New York, 5 de dezembro de 1928. Fundo Arthur Neiva/ AN 18/06/1921).

Em 31 de maio de 1929, Arthur Neiva foi nomeado como Secretário de Estado dos Negócios do Interior de São Paulo e permaneceu à frente do Instituto Biológico (RIBEIRO, 1997; SILVA, 2006) com atividade científica bastante dinâmica. Não por acaso, a discussão das cartas nesse período gira em torno da produção agrária exportadora brasileira, com temas que abordam desde críticas aos excessos da produção de café (Carta de Lobato a Neiva em 5 de abril de 1929. Fundo Arthur Neiva/ AN 18/06/1921) ${ }^{6}$, passando pela previsão de uma crise do produto e da indústria da borracha que perde mercado para a Ásia por falta de ciência na produção, chegando a observações sobre a inexistência de mercado para a banana, controlado pelos norte-americanos no Caribe (LEAL, 2020).

\section{A entrada de Arthur Neiva na política baiana e o início da campanha de Monteiro Lobato pelo petróleo no Brasil}

A chamada "revolução" de outubro de 1930 teve em Arthur Neiva um aliado tenaz, que estabeleceu estreito contato com o grupo dos tenentes. A amizade com um dos representantes destes, João Alberto Lins de Barros, e as conturbadas disputas de poder que marcaram o início do governo provisório de Getúlio Vargas levaram Neiva ao palco político. Em 1930, João Alberto, nomeado interventor federal em São Paulo, designou-o secretário do interior do Estado, quando ele criou o primeiro Departamento de Educação Física no país (DALBEN et al., 2019), um Serviço de Assistência aos Psicopatas, bem como ordenou a reorganização do Instituto Bacteriológico de São Paulo, extinto em 1925 (BORGMEIER, 1940).

De acordo com Leal (2020), antes de Monteiro Lobato voltar dos Estados Unidos para o Brasil, ele enviou uma carta a Getúlio Vargas sobre as conclusões a que chegou

\footnotetext{
${ }^{6}$ Na carta de Arthur Neiva enviada a Monteiro Lobato em meses seguintes, no dia 30 de julho de 1929, o cientista diz acreditar que a laranja poderia se tornar o produto de exportação que sucederia o café na economia brasileira.
} 
com sua experiência norte-americana. A cópia da correspondência enviada ao presidente foi encaminhada para Arthur Neiva. No texto, "Lobato supunha que os grandes problemas nacionais eram a falta de investimento em ferro, combustível e trigo, ocasionando a fraqueza da economia brasileira" (LEAL, 2020: 129). O literato acreditava na mudança nos rumos da economia com a introdução da indústria de base, pois parecia ser inicialmente compatível com a proposta do presidente Vargas. Assim, Lobato demonstra uma visão moderna para a economia da nação, na medida em que os projetos propostos visavam uma integração territorial e alvejavam a autossuficiência nos moldes do que ocorreu nos Estados Unidos:

Acho de meu dever apresentar a Vossa Excelência algumas das conclusões a que cheguei, com respeito a vários problemas brasileiros, durante minha estadia na América. Como são conclusões meditadas e baseadas em factos, espero que não redundará em perda de tempo os minutos que Vossa Excelência despender em lê-las. O exame das importações do Brasil revela três hipertrofias que por si só explicam a fraqueza da nossa situação econômica: trigo, ferro e combustível. A redução dessas hipertrofias equivalerá ao aumento de exportação que a balança comercial está pedindo e não temos conseguido. Que não temos conseguido e difícil se faz conseguir, dado o fenômeno notório da superprodução dos artigos que produzimos nenhum dos quais constitui monopólio nosso e, portanto, não encontra escoadouro livre de concorrência, parece-me linha de menor resistência atacar as importações, obtendo por meio da redução delas o ouro que tão cedo não podemos obter pelo aumento da exportação. Ferro. É o nosso problema básico, cuja solução resolverá automaticamente uma série de outros problemas até aqui apenas ladeados [...]. Tenho a honra de apresentar a Vossa Excelência os protestos da minha mais alta consideração. A sua excelência o senhor doutor Getúlio Vargas. Presidente da República dos Estados Unidos do Brasil (Carta de Lobato a Getúlio Vargas em 9 de dezembro de 1930. Fundo Arthur Neiva/ AN 18/06/1921).

De volta a São Paulo, Lobato dedicou-se às campanhas do ferro e apresentou um "Memorial" ao chefe do governo, Getúlio Vargas, no qual tocou na questão siderúrgica na correspondência do dia 13 de junho de 1931 (Carta de Lobato a Neiva em 13 de junho de 1931. Fundo Arthur Neiva/ AN 18/06/1921). Nesse contexto, ele fundou o Sindicato 
Nacional de Indústria e Comércio e a Companhia Petróleos do Brasil, voltados, respectivamente, à exploração do ferro e do petróleo. Iniciou também nessa época suas denúncias contra os contratos mantidos pelo governo com a Itabira Iron Ore Company. Monteiro Lobato denunciava o governo por forjar laudos que afirmavam a não existência de petróleo no Brasil, com o propósito de favorecer as empresas estrangeiras interessadas em manter inexploradas as reservas petrolíferas brasileiras. ${ }^{7}$

Em 1931, o engenheiro Edson de Carvalho iniciou os trabalhos de perfuração em Riacho Doce, Alagoas. No ano seguinte, anunciou à imprensa a descoberta de imensas reservas na região e associou-se a Monteiro Lobato para criar a Companhia Petróleo Nacional. Enquanto isso, na Bahia, outro engenheiro, Manuel Inácio Bastos e Oscar Cordeiro, presidente da Bolsa de Mercadorias daquele Estado, tentou conseguir apoio do governo federal para explorar vestígios de petróleo na região de Lobato. Em agosto desse mesmo ano, deu-se início as buscas por petróleo em Araquá no Estado de São Paulo. O Ministério da Agricultura negou auxílio técnico e material a essas iniciativas privadas, alegando que não existia petróleo nas regiões indicadas. Pelo fato da "disputa entre órgãos públicos e empresas privadas que se estabeleceu o debate sobre a existência de petróleo no Brasil" (LEAL, 2020: 130). As companhias privadas nacionais tiveram que enfrentar a centralização do poder político e o crescente controle estatal da economia.

Em paralelo ao início da campanha pelo petróleo empreendida por Lobato, em 1931, Arthur Neiva foi convidado pelo interventor federal em São Paulo, João Alberto Lins de Barros, a assumir o cargo de interventor federal da Bahia, deixando assim a sua função na Secretaria do Interior do estado de São Paulo. Em carta, Lobato parabenizou seu amigo pelo novo cargo: "Li hoje no Times a sua escolha para interventor na Bahia e não resisti a tentação de lhe mandar parabéns - embora seja a Bahia que os mereça" (Carta de Lobato a Neiva em 13 de fevereiro de 1931. Fundo Arthur Neiva/ AN 18/06/1921). No governo baiano, Arthur Neiva procurou desenvolver serviços sanitários, e em 8 de junho de 1931, junto ao Secretário da Agricultura, Joaquim Inácio Tosta Filho, criou o Instituto do Cacau, com a finalidade de defender os interesses da lavoura cacaueira, um órgão sem finalidades comerciais ou lucrativos.

Cabe ressaltar que, antes do apoio de Arthur Neiva e contato com o grupo dos tenentes da "revolução de 1930", o cientista fundou Instituto Biológico em dezembro de

\footnotetext{
7 CPDOC/ FGV. Monteiro Lobato. Biografia. Disponível em: 〈https://cpdoc.fgv.br/producao/dossies/AEraVargas1/biografias/monteiro_lobato>. Acesso em: 20 de janeiro de 2020.
} 
1927, fruto das articulações de Arthur Neiva e de seu ideário de pesquisa científica (LEAL, 2020; SILVA, 2006; RIBEIRO, 1997). E, de certa forma, reverberando o perfil institucional que Oswaldo Cruz (BRITTO, 2006) implementou em Manguinhos, Neiva procurou criar um espaço de produção de novos conhecimentos, sem deixar de atender às demandas práticas da agropecuária paulista. Três anos depois, o cientista apoiou a "revolução de 1930" e estabeleceu que o provocasse o seu afastamento do estado de São Paulo. Acerca desse contexto governamental, na carta abaixo, Monteiro Lobato descreve a fúria política no âmbito paulista e o seu entusiasmo com o início do voto secreto no Brasil:

Andamos aqui a formar um grupo de conspiradores com o fim de reintegrar no cérebro de S. Paulo um lóbulo que fugiu e está fazendo falta séria - um lóbulo chamado Arthur Neiva. Maneco ${ }^{16}$ é o chefe da camorra, e com aquela língua de serpente do Éden, cada vez com maior prestígio em virtude das barbas cada vez mais brancas, esfarripadas e jeovistas, vai insinuando venenos discretíssimos contra os seus inimigos (inimigos de Neiva) e inoculando biotômicos estratégicos aos seus amigos, de modo a pô-los em eretismo ativo [...] S. Paulo agora está mais interessante do que nunca. Uma fúria política, das criadoras. Até eu me alistei - e a mulher e a filharada. Formamos um bloco de sete eleitores - número suficiente para fazer alguém ganhar ou perder uma eleição. Isso do eleitor poder votar secretamente de acordo com a sua consciência está parecendo maravilha até aos próprios pererês de baixo. E em consequência as futuras políticas paulistas vão ser cheias de surpresas [...] que agora, com o voto secreto, tem meios de se manifestar. Ora, um S. Paulo assim renovado, graças à abençoada getulice que atirou no que viu e matou para sempre a desgraça que era um regime no qual o voto já saia falsificado dentro do votante, quem por medo não vota em quem quer, falsificar o próprio voto, não pode dispensar o concurso do seu grande paulista por engano nascido na Baía. $^{8}$

Diversas vezes nas cartas Monteiro Lobato expressou a sua visão sobre a

\footnotetext{
${ }^{8}$ Manuel Lopes de Oliveira Filho (1872 - 1938), amigo de Lobato e Arthur Neiva, importante entomologista do período. Ver mais: MELO, Luís Correia de (1954). Dicionário de autores paulistas. São Paulo: Comissão do IV Centenário da Cidade de São Paulo.
} 
“revolução de 1930” e criticou a estrutura oligárquica da Primeira República ${ }^{9}$. Considera a transição uma renovação política - "matou para sempre a desgraça que era um regime no qual o voto já saia falsificado.” Dessa forma, nesse período das correspondências há duas interpretações acerca do "Movimento da Constituinte de 1932" pelos missivistas: enquanto Lobato apesar de crítico demonstrava-se satisfeito com o fim do voto de cabresto típico das oligarquias estaduais na carta de 23 de julho de 1934, o cientista Arthur Neiva expressava insatisfação na correspondência de 14 de agosto de 1934.

Arthur Neiva enfrentava o cenário político de colisão com as elites paulistas, quando estas, em 1932, instalaram uma revolta contra as iniciativas centralizadoras do governo de Getúlio Vargas. Arthur Neiva foi obrigado a deixar São Paulo em circunstâncias bastante controversas, tão logo rebentou a chamada "revolução constitucionalista". O vínculo de Arthur Neiva com João Alberto e outros tenentes "tornaram-no persona non grata no território paulista, obrigando-o a abandonar a direção do Instituto Biológico, que passou às mãos de Henrique da Rocha Lima” (SILVA, 2011: $31)$.

Em carta-manifesto dirigida a Waldemar Ferreira, secretário da Justiça e Segurança Pública do Governo Constitucionalista Revolucionário de São Paulo, Lobato fez críticas ao "militarismo federal", considerando a insurreição uma "guerra de independência". Ele declara em carta: "São Paulo, depois da vitória, deverá expressar-se na fórmula Hegemonia ou Separação", título que deu à sua carta manifesta. Já Neiva, como revela carta de 14 de agosto de 1934, apoiou a revolução porque não a considerava separatista. Colocou-se, junto com o Instituto Biológico, do qual era diretor, às ordens de São Paulo, entregando um ofício com essa informação ao Dr. Francisco Junqueira, secretário da Agricultura. No entanto, "Henrique Rocha Lima teria se adiantado à Neiva, denunciando às autoridades rebeladas o cientista por seus vínculos com os tenentes" (LEAL, 2020: 136).

Quando Rocha Lima retornou para Brasil em 1928, ele foi convidado por Arthur Neiva para fazer parte do Instituto Biológico de São Paulo. Lima aceitou o convite e decidiu permanecer definitivamente no país. No início da Era Vargas, em defesa do Instituto Biológico, Rocha Lima se empenhou em apresentar às autoridades

\footnotetext{
${ }^{9}$ Na obra "Urupês" (1918), Monteiro Lobato crítica ao sistema eleitoral e o direito de voto aos mais pobres. A representatividade política como direito apenas dos homens considerados cultos é reafirmada. Na interpretação de Lobato, os homens pobres de cultura e educação como Jeca Tatu, não sabem votar e são analfabetos políticos.
} 
administrativas a relevância da atividade científica na promoção do desenvolvimento da agricultura e pecuária. As relações pessoais e políticas definiam o perfil de ação dos administradores dos institutos científicos do país. Nesse sentido, é válido refletir como os cientistas estão imersos em processos e em articulações que tornam possíveis as suas carreiras (BIAGIOLI, 2006).

O Estado Varguista foi caracterizado pelo intervencionismo e autoritarismo, conferindo um processo de controle das ações de saúde pública em todo o país (HOCHMAN, 1993). Houve um intenso processo de organização, profissionalização, despolitização e burocratização. A saída repentina de Arthur Neiva do Instituto Biológico (Carta de Neiva a Lobato em 14 de agosto de 1934. Fundo Arthur Neiva/ AN 18/06/1921) deve ser considerada como resposta as articulações políticas do cientista, não por acaso que ele estava ligado ao grupo de forças que assumiu o poder com Getúlio Vargas em outubro de 1930 (SILVA, 2011: 601).

De volta ao Rio de Janeiro, Neiva ocupou em janeiro de 1933 a recém-criada Diretoria-Geral de Pesquisas Científicas do Ministério da Agricultura, sob a qual ficaram submetidos o Instituto de Meteorologia, o Instituto de Geologia, o Instituto de Química, o Instituto de Biologia Animal e Vegetal, além da Estação Experimental de Combustíveis e Minérios. Ainda em 1933, Neiva assumiu a direção do jornal carioca A Nação, fundado pelo tenente João Alberto e tendo como redator-chefe Azevedo Amaral, figura central na formulação do ideário que serviu de base ideológica para o governo, implementada posteriormente no Estado Novo.

\section{A legislação de 1934 e as intervenções na exploração do petróleo brasileiro}

O governo constitucional realizou um programa de reformas com novos princípios de intervenção do Estado no domínio econômico. Cuidou desde logo da elaboração de dois grandes códigos, o de Águas e o de Minas, que visavam estimular o desenvolvimento das riquezas de fundamental importância para o interesse nacional. A elaboração do Código de Minas processou-se no Ministério da Agricultura, sob a orientação do ministro Juarez Távora, ao mesmo tempo em que se elaborava a nova Constituição. Promulgado em 10 de julho de 1934, somente foi publicado no Diário Oficial no dia 20 de julho (BRASIL, 1934), após, portanto, a promulgação da nova Constituição, em 17 de julho. Foi nesse arranjo que a discussão sobre a compatibilidade no Código de Minas e a nova 
Constituição foi estabelecida no Supremo Tribunal Federal (STF). ${ }^{10}$

Monteiro Lobato criticava a legislação e chegou a apelar para autoridades, na tentativa de alterar o Código de Minas, pois entendia que, havia pelo menos dois grupos estrangeiros interessados no petróleo brasileiro, mencionados em muitas das cartas: os norte-americanos, que teriam "interesses ocultos" (CHIARADIA, 2008: 32), representados por Vitor Oppenheim e pela Standard Oil, e os alemães, representados por Frankie e pela empresa Piepmeyer, entre outros. O governo federal havia decretado o fim de qualquer atividade dos governos estaduais no setor de mineração, cabendo apenas à União o direito de autorizar a pesquisa e a lavra dos recursos minerais. Antes eram responsabilidades do Ministério da Agricultura que, sob o comando de Juarez Távora, passou por uma profunda reestruturação que pretendia agilizar e centralizar as atividades do órgão.

Nessa conjuntura a Cia. Nacional de Petróleo e a Royal Dutch \& Shell passaram a funcionar legalmente no Brasil (LEAL, 2020). Entre 1932 e 1935, outras duas companhias passaram a atuar no Brasil: a Companhia Petróleo Nacional, incorporada por Monteiro Lobato, Lino Moreira e Edson de Carvalho, que funcionava legalmente em Riacho Doce, Alagoas; e a Companhia Petróleos do Brasil, presidida por Lobato, instalada legalmente desde 1932 no interior de São Paulo. Nesse período, Lobato se associou à pesquisa da petrolífera Alliança Mineração e Petróleos LTD, a AMEP, um departamento da Companhia de Petróleo Nacional. Mesmo com as empresas estruturadas para o serviço, não se extraía oficialmente petróleo do subsolo brasileiro.

Segundo Kátia Chiaradia (2008, 2016), em 1933, o Serviço Geológico e Mineralógico do Brasil, que marcara a entrada do Estado no setor petrolífero, foi extinto. O órgão atuara de 1919 até aquele momento, realizando pouquíssimas perfurações e em apenas sete estados: Alagoas, Bahia, Pará, Paraná, Rio Grande do Sul, Santa Catarina e São Paulo. Nesse período, Juarez Távora solicitou oficialmente ao Itamaraty uma organização do exterior para estudos geofísicos no Brasil (CHIARADIA, 2016).

Em março de 1934, o Departamento Nacional da Produção Mineral foi substituído pela Agência Nacional de Mineração, presidido por Fleury da Rocha, figura com a qual Lobato travou uma longa batalha. O órgão passou a comandar as iniciativas de pesquisa de petróleo em território brasileiro. De acordo com Chiaradia (2016), a nova legislação

\footnotetext{
10 CPDOC/FGV. Código de Minas. Temático. Disponível em: <http://www.fgv.br/cpdoc/acervo/dicionarios/verbete-tematico/codigo-de-minas>. Acesso em: 22 jan. 2020 .
} 
estabelecia "a nacionalização das jazidas e minas julgadas básicas ou essenciais à defesa econômica ou militar do país" e "a exigência de nacionalidade brasileira ou de constituição de uma empresa nacional para atuar no setor de mineração" - medidas nitidamente nacionalistas.

Monteiro Lobato encontrou uma brecha e organizou no Brasil sociedades com capital estrangeiro, como foi o caso da Aliança Mineração e Petróleos, que consolidou a união entre o literato-empresário e os alemães (CHIARADIA, 2016). Ele não permitiria que o petróleo brasileiro ficasse exclusivamente com o truste americano Standard OilRoyal Dutch, que o escritor imaginava estar por trás do imbróglio, sem oferecer uma concorrência mínima. De acordo com Chiaradia (2008), o código de 1934 preservou a propriedade privada das minas que estivessem em lavra até 17 de julho daquele ano, estabelecendo um procedimento administrativo chamado manifesto, pelo qual os interessados em jazidas e minas conhecidas deviam declarar ao governo a sua existência e os direitos constituídos sobre as mesmas. ${ }^{11}$ Estabeleceu dois regimes diversos para exploração das minas de propriedade privada: as minas, em lavras ainda que transitoriamente suspensas à data da promulgação da Constituição, poderiam ser exploradas independentemente de autorização ou concessão; as minas ou jazidas que não tivessem sido lavradas, embora continuassem de propriedade privada, somente mediante concessão ou autorização do governo poderiam ser exploradas, estando assegurada ao proprietário preferência pela lavra ou participação nos resultados (CHIARADIA, 2016, 2008).

Monteiro Lobato começou uma campanha para convencer a população e os governantes da existência de petróleo no país e a necessidade de explorá-lo para nos transformarmos em uma nação desenvolvida (CHIARADIA, 2008). Além da falta de interesse governamental, para Monteiro Lobato, o petróleo não era encontrado no Brasil devido aos interesses das grandes companhias multinacionais. Na carta de 12 de fevereiro de 1935, Arthur Neiva comenta com Monteiro Lobato as suspeitas sobre o petróleo no bairro Lobato na Bahia, cujo resultado só foi confirmado quatro anos depois. A informação de Neiva enviada a Monteiro Lobato era confidencial e exclusiva do Instituto de Tecnologia:

${ }^{11}$ CPDOC/ FGV. Verbete: Código Minas. Fonte: BEDRAN, E. Mineração; CALÓGERAS, J. Minas; PINHEIRO, A. Direito; ROCHA, L. Código; VENÂNCIO FILHO, A. Intervenção; VIVACQUA, A. Disponível em: http://www.fgv.br/cpdoc/acervo/dicionarios/verbete-tematico/codigo-de-minas. Acessado em: 20 mai. 2020. 
Envio-lhe uma informação reservada, para seu uso exclusivo. Outro dia fui ao Instituto de Tecnologia. Estive com o Fonseca Costa $^{12}$ de quem eu sou amigo. Ele mostrou-me o que está fazendo lá a seu pedido. Não se trata, porém, deste assunto, mas de outro muito mais interessante. Contou-me ele o seguinte: - $\mathrm{Na}$ Bahia existe um lugar que se chama Lobato e lá, de uns tempos a esta parte, fala-se muito em petróleo. Ninguém acreditava. Apareciam análises erradas ou erradíssimas, como a última feita por tal Carneiro, lente da Escola Politécnica da Bahia. Ninguém levava a sério a coisa, mas de repente o Fonseca $\operatorname{Costa}^{24}$ recebeu material colhido e condições que lhe foi remetido e a análise feita pelo Sylvio Froes de Abreu, elemento de grande valor, mostrou que, de fato, existe petróleo e acredita não se tratar de nenhuma intrujice porque as amostras foram colhidas por pessoa de idoneidade [...]. Dou essa informação sob sigilo (Carta de Neiva a Lobato, de 12/02/ 1935. Fundo Arthur Neiva/ AN 18/06/1921).

Posteriormente, na carta do dia 9 de abril de 1935, Arthur Neiva pôde complementar os dados da carta acima, pois informou que começou o trabalho com Ernesto Lopes da Fonseca Costa, engenheiro geógrafo e integrante da Diretoria Geral de Pesquisas Científicas do Ministério da Agricultura. Participaram da Diretoria o Instituto de Meteorologia, o Instituto de Geologia e o Instituto de Biologia Animal, no que seria uma primeira e efêmera tentativa de criar uma agência central de pesquisas científicas no país. Arthur Neiva instalou seu gabinete no novo prédio do Instituto de Tecnologia, ao lado de Fonseca Costa (CASTRO; SCHWARTZMAN, 2008). Devido à intensa pesquisa, nas cartas Lobato e Neiva se familiarizam com alguns termos técnicos geológicos da exploração petrolífera. O cientista demonstra-se preocupado com a questão do petróleo e do câmbio em libras das empresas Standard Oil e a Casa Ford, pois calculava os custos para a nação brasileira caso não fosse encontrado o petróleo,

\footnotetext{
${ }^{12}$ Ernesto Lopes da Fonseca Costa formou-se engenheiro geógrafo e engenheiro civil em 1913, pela Escola Politécnica, atual Escola de Engenharia da Universidade Federal do Rio de Janeiro. Em 1928 tornou-se professor catedrático de Metalurgia da mesma Escola. Foi também professor da Pontifícia Universidade Católica e do Instituto Militar de Engenharia - então Escola Técnica do Exército. Foi diretor do Serviço Geológico e Mineralógico do Brasil, participou da Diretoria Geral de Pesquisas Científica do Ministério da Agricultura dirigida por Arthur Neiva (1880-1943), com a denominação de Instituto de Tecnologia. Fonte: Ernesto Lopes da Fonseca Costa, O Instituto Nacional de Tecnologia e seus Fins, Rio de Janeiro, Ministério do Trabalho, Indústria e Comércio, Instituto Nacional de Tecnologia, 1934.
} 
Já dei os passos junto ao Fonseca Costa que se interessou bastante pelo assunto e está manobrando para obter informações. Soube com toda segurança que agentes alemães estão na Bahia trabalhando, sob grande reserva, com o interventor de lá para explorarem xistos betuminosos de marahu que pode dar $35 \%$ de óleo [...]. O petróleo deve vir, de outro modo não sei para onde iremos [...]. Se não houver um imprevisto, estou convencido que dentro de 2 anos, o Brasil não poderá pagar suas dívidas [...] Imagine que alguns contam que sairemos das nossas dificuldades com a inevitabilidade da guerra (Carta de Neiva a Lobato, de 12/02/ 1935. Fundo Arthur Neiva/ AN 18/06/1921).

Na carta de 21 de maio de 1935, Arthur Neiva escreveu acerca do seu incômodo com o descaso governamental na mobilização de cientistas nacionais para articular a questão do petróleo. A partir daí, o cientista sinalizou para Monteiro Lobato o interesse dos alemães sobre o petróleo nacional (Carta de Neiva a Lobato em 09/ 04/ 1935. Fundo Arthur Neiva/ AN 18/06/1921). Em cartas posteriores enviadas a Arthur Neiva, Monteiro Lobato mencionou o contrato geofísico assinado e o projeto da sua empresa Companhia Mato Grosso de Petróleo, e os primeiros contatos com a empresa alemã ELBOF da qual Frankie era representante técnico:

Assinamos lá o contrato geofísico e vamos agora lançar a Companhia Mato Grosso de Petróleo, em começos de dezembro. Ontem recebemos um telegrama da Paraíba, comunicando a assinatura de igual contrato com a Elbof [...] Li as notícias da inauguração do Instituto do Cacau. A sua passagem tão rápida pelo governo da Baía ficará eternamente assinalada por aquela obra magnífica. Se cada governo fizesse uma coisa assim, iríamos longe. Tive a visão de conjunto do curiosíssimo e imenso Pantanal. Há trechos maravilhosos de beleza - o das lagoas. Parece um jardim. Na região do Rio Negro, onde temos contrato de subsolo, existem, contadas pelo Rondon, 170 lagoas, das quais 95 de água salgada [...]. A campanha consiste em fazer estudos geofísicos e perfurar. Só. O resto se resume em literatura de relatórios - wild talk. O empenho do Ministério é agora perfurar em Alagoas para tirar petróleo antes do Edson. Para isso removeram para lá o material de sondagem existente no Paraná. Ótimo. Que se tire petróleo é o que quero (Carta de Neiva a Lobato em 21/ 05/ 1935. Fundo Arthur Neiva/ AN 18/06/1921). 
Em junho de 1935, foi publicada pela Companhia Editora Nacional “A Luta pelo Petróleo”, escrito por Essad Bey e traduzido por Charles W. Frankie, uma colaboração de Lobato, que escreveu um polêmico prefácio (Carta de Lobato a Neiva sem data. Fundo Arthur Neiva/ AN 18/06/1921). ${ }^{13}$ A obra denuncia a ineficiência do Serviço Geológico e demais órgãos do governo na exploração de recursos naturais. Em carta enviada a Arthur Neiva em 16 de julho de 1935, Monteiro Lobato comentou sobre a entrega do livro de Essad Bey aos congressistas (Fundo Arthur Neiva/ AN 18/06/1921. Carta de Lobato a Neiva, 22/05/1935). Em Alagoas, em um poço da empresa de Lobato, a Companhia Petróleo Nacional sob o estudo de Oppenheim contrariava a crença no petróleo litorâneo. Mais tarde, isso viria a ser desmentido por técnicos alemães próximos ao escritor. No diálogo do dia 5 de junho de 1935, Arthur Neiva confirmou o esforço de Oppenheim, representante do Estado, em negar a existência de petróleo, local onde Monteiro Lobato bradava o oposto de forma visceral:

O trabalho de Oppenheim foi publicado pelo Serviço Geológico sob a direção do Fleury [...]. Em resumo, o trabalho diz que no Brasil não pode haver petróleo a não ser nos limites do Brasil com a Bolívia e com o Peru. Para mim, havendo esta distância, mesmo que ele jorre naquela altura, economicamente não será explorado. A publicação em questão tem número 5; mande buscar. $\mathrm{O}$ homem inventa uma teoria e dá um mapa mostrando que na região denominada Gondwana, a qual inclui o Brasil e certa parte da África, o petróleo se encontra no terreno cretáceo e terreno cretáceo a gente acha até no Estado do Rio e na Bahia, justamente naquela zona que tem o nome de Lobato, etc. Agora um ponto importante. Puseram-me numa tal comissão mista para salvar a pátria em 4 meses, e eu sou um dos dez trouxas. Querem que o Brasil que não pode ser salvo com 4 anos de governo direcionado, seja por um trabalho de falir transformado por decúria sob as ordens do Ministro da Fazenda de quem aliás, tenho impressão favorável. Aí, expondo a possibilidade da existência do Petróleo no Brasil, com Victor Oppenheim, teorias gondwaicas e patati- patatá, eu afirmei que tudo era uma pilhéria, embora pudesse admitir que houvesse fundamento e fosse verdadeira, necessitava comprovação [...]. Ora, o Brasil, terra do tamanho de um continente, cuja triangulação ainda não se fez, que nos melhores mapas a gente

\footnotetext{
13 Segundo as informações apresentadas nas cartas tudo indica que foi escrita no ano de 1936, período da inauguração do Instituto do Café.
} 
encontra deslocadas cidades e acidentes geográficos de importância, verifiquei no Piauí, como é que se pode afirmar qualquer coisa de seguro se não há nenhuma pesquisa séria de subsolo? (Carta de Neiva a Lobato, de 05/06/1935. Fundo Arthur Neiva/ AN 18/06/1921).

No Boletim de Agricultura, Oppenheim publicara, também, trechos de seu relatório sobre a região de Lobato: “A Questão do Petróleo da Bahia”. Afirmava-se que na localidade Lobato na Bahia, do ponto de vista da geologia de petróleo, era desfavorável à presença de hidrocarbonetos. $\mathrm{O}$ conjunto geotectônico desse local é absolutamente negativo. Os elementos técnicos atestavam de um modo formal a não existência de jazidas petrolíferas na região. De acordo com Kátia Chiaradia (2016, 2008), entre os anos de 1934 e 1937 foram estreitadas as relações entre o escritor e o engenheiro do petróleo Karl Werner Frankie, suíço imigrado em 1920, que no Brasil mudou de nome, passando a ser "Charley Frankie" - também chamado de Charles pelos amigos. Para Lobato, o comportamento da Standart Oil era o mesmo de um "Octopus" ou polvo, disfarçando-se em empresas ou órgãos nacionais para, quando fosse interessante, prender sua vítima, ou seja, os "petroleiros brasileiros". ${ }^{14}$

Edson de Carvalho era sócio de Monteiro Lobato na Companhia Petróleo Nacional, uma pessoa de confiança para administrar os negócios em Maceió. Na correspondência de Lobato a Neiva, ele cita a parceria com seu sócio e lamenta o fim do contrato geofísico, o qual possibilitava os estudos sísmicos para a exploração do petróleo. Considera que o governo federal por via militar atrapalhava o progresso do seu empreendimento: "A coisa federal sempre, sempre. Ora, esses estudos sísmicos são fundamentais para complemento dos já feitos pelos processos - e o contrato vai chegar ao fim sem que a parte sísmica se realize. Estas coisas dão-me náuseas. Sinto vontade de vomitar-me a mim mesmo. Repugnante um país assim” (Carta de Neiva a Lobato, de 12/ 04/1936. Fundo Arthur Neiva/ AN 18/06/1921).

Na correspondência de 15 de maio de 1936, Arthur Neiva menciona os desafios da burocracia estatal em Alagoas e das exigências sem fim desse processo do negócio do

\footnotetext{
${ }^{14}$ Em entrevista sobre a sua tese, Kátia Chiaradia sobre afirma que no livro "O Escândalo do Petróleo", Monteiro Lobato toma o cuidado de não deixar claro que se tratava da empresa, pois o assunto é tratado em uma das cartas a Frankie: "Não podemos acusar a Standard. Sabemos que no fundo de tudo está o Octopus, mas, em vez de falar em Standard, temos de dizer os Interesses Ocultos". Poder, literatura e petróleo. Ver: LAURETTI, Patrícia (2016). Poder, literatura e petróleo. Pesquisadora analisa e comenta troca de correspondência entre Monteiro Lobato e engenzheiro suíço radicado no país. Disponível em: https://www.unicamp.br/unicamp/ju/678/poder-literatura-e-petroleo. Acessado em: 20 dez. 2019.
} 
petróleo. Arthur Neiva estava demasiadamente angustiado, ao ponto de expressar "um grito d'alma" para sair do Brasil e mudar-se para os Estados Unidos ou Inglaterra, sonhava em ser reconhecido no exterior, não suportava mais o sistema institucional brasileiro. Encontrava-se desiludido com os rumos da nação, era uma desgraça para o cientista ter nascido no Brasil:

Burocracia, diz V., a propósito dos entraves criados para a remessa do material para Alagoas; burocracia deverá ser com mais precisão. Os diretores das repartições cada vez mais se vêm atados com as exigências bizantinas [...]. Meu caro Lobato vai agora um grito d'alma. Se eu pudesse, de repente, com minha família todinha, aparecer milagrosamente nos Estados Unidos, ou na Inglaterra, eu começaria a acreditar num poder eterno, esmagado e, sobretudo reconhecido pelo milagre e começaria a fazer propaganda da sua existência. Estou chumbado a esta droga até o último galego e provavelmente ainda terei a desgraça de ir servir depois da morte, indiretamente para alimentar tiririca ou capim para nutrir a gente burra do Brasil (Carta de Neiva a Lobato, de 15/05/1936. Fundo Arthur Neiva/ AN 18/06/1921).

Nas cartas trocadas entres os amigos é possível identificar menções a livros e leituras, seja na parceria da tradução ou na organização e compilação de "O Escândalo do Petróleo”. Segundo Kátia Chiaradia (2016), Monteiro Lobato e Charles Frankie estavam preocupados com o fato de engenheiros ligados à empresa norte-americana Standart Oil atestarem para o governo brasileiro que não havia petróleo no Brasil. Em entrevista, Chiaradia afirma que "Lobato ficou conhecido como o 'pai' da Petrobrás, porque sempre foi contra a pesquisa americana no Brasil" (LAURETTI, 2016). Lobato não era a favor da participação das empresas norte-americanas na exploração do petróleo por via do Estado brasileiro, a sua defesa era pela iniciativa privada nesse setor devido às propostas de parceria com a empresa alemã ELBOF. Nesse período, Lobato e Neiva frequentemente descrevem o sentimento de desânimo, de desgosto com o desenvolvimento da ciência brasileira e angústias sobre o futuro da nação.

Em 1937, Monteiro Lobato publicou “O Poço do Visconde”, décimo volume da série "obras completas" de ficção para crianças. A obra foi censurada, pois Lobato afirmou que os peritos do governo de Vargas negavam a existência de petróleo no Brasil. Meses antes de pôr fim a sua campanha pela incessante busca por petróleo, Monteiro Lobato escreveu a Neiva a sua total amargura com o Brasil, expressando o sentimento de 
fracasso de uma vida dedicada às questões nacionais. Ele lamenta ao seu amigo a sua trajetória em defesa do setor petrolífero nacional e a falta de retorno e reconhecimento em sua luta:

\begin{abstract}
A impressão última que levarei da vida é essa: a mais sórdida canalhice. Veja o petróleo. Dez anos levei como um maluco vivendo o petróleo. A ideia final venceu. Mas venceu também a sabotagem oficial [...]. O Conselho Nacional do Petróleo não dá a autorização necessária... Ora, que desejo pode ter um homem como eu, num país como este, numa época em que tais coisas acontecem sem que a visita sequer tenha o direito de queixar-se? Um só: morrer. Mas não morrerei antes de acabar a leitura do seu livro. É o meio que tenho de prolongar por mais um pouco as nossas inesquecíveis conversas de outro... da Revista do Brasil... da Brama... de Iguape... Saudosos tempos! (Carta de Lobato a Neiva, de 25/04/1940. Fundo Arthur Neiva/ AN 18/06/1921).
\end{abstract}

A incansável atuação na campanha do petróleo levou a prisão de Monteiro Lobato em janeiro de 1941. Foi acusado de injuriar o Presidente da República, o Conselho Nacional do Petróleo e o Departamento Nacional de Produção Mineral (DNPM). Também levantaram indícios de crime contra a economia popular e ligação com interesses estrangeiros, notadamente de empresas alemãs. Ironicamente, enquanto Lobato estava preso, foi publicada a primeira legislação específica para o petróleo, o decreto-lei 3.236 (BRASIL, 1941), de 7 de maio de 1941, autoriza a realização de pesquisas para essa área.

A relação entre Getúlio Vargas e Monteiro Lobato desenrolou-se de maneira bastante irregular, alternando momentos de aparente concordância ideológica e divergências extremas. Após a saída da prisão em julho de 1941, Monteiro Lobato abandonou a luta pela exploração do petróleo, não participou das discussões sobre o petróleo brasileiro e da iniciativa privada nacional no setor de pesquisa e exploração.

Conclui-se que o projeto americanista, a campanha pelo ferro e petróleo no Brasil nas correspondências de Monteiro Lobato e Arthur Neiva, possui forte diálogo com a agenda dos intelectuais brasileiros da década de 1930. As cartas foram escritas no período de crise do liberalismo, momento oportuno para os intelectuais assumirem os seus projetos para "salvar" o Brasil. Dentre as soluções propostas estava a necessidade de consolidar a nacionalidade, conferir maiores prerrogativas ao poder central em detrimento 
dos poderes locais e substituir os fundamentos institucionais do Estado brasileiro. Em diversos momentos, os diálogos de Neiva e Lobato expressam um tom de pessimismo em relação aos projetos nacionais, e ao mesmo tempo, uma intensa vontade de transformar o Brasil numa nação viável. Vimos que o gênero epistolar neste trabalho pôde contribuir na ampliação do horizonte acerca do repertório dos intelectuais no período que se estende do final da Primeira República ao Estado Novo.

\section{Fontes}

Centro de Pesquisa e Documentação de História Contemporânea no Brasil (CPDOC/ FGV). Arquivo Arthur Neiva. Fundo pessoal. Correspondência entre Arthur Neiva e Monteiro Lobato. Localização: AN c 1918.06.21. Série: c Correspondência / Data de produção: 21/06/1918 a 02/10/1942. Quantidade de documentos: 143 (227 folhas).

\section{Referências bibliográficas}

BENCHIMOL, J. L \& TEIXEIRA, L.A (1993). Cobras, Lagartos e outros bichos. Uma história comparada dos Instituto Oswaldo Cruz e Butantan. Rio de Janeiro: UFRJ/ Fiocruz. Casa de Oswaldo Cruz.

BRASIL (1934). Legislação. Decreto $\mathrm{n}^{\circ}$ 24.642, de 10 de julho de 1934. Câmara dos deputados. Disponível em: https://www2.camara.leg.br/legin/fed/decret/19301939/decreto-24642-10-julho-1934-526357-publicacaooriginal-79587-pe.html.

Acessado em: 20 out. 2020.

BRASIL (1941). Legislação Informatizada. Título I - Das jazidas de petróleo e gases naturais. Capítulo I. Câmara dos deputados. Disponível em:<www2. camara.leg.br>. Acessado em: 20 jul. 2021.

BIAGIOLI, Mario (2006). Galileu, Cortesão. A Prática da Ciência na Cultura do Absolutismo. Coleção: História e Filosofia da Ciência. Portugal: Porto Editora.

BORGMEIER, T (1940). Arthur Neiva: a propósito do seu $60^{\circ}$ aniversário. Revista de Entomologia. Rio de Janeiro, v.11, n. 1/2, pp.1-104.

CASTRO, M.HM., SCHWARTZMAN, S. (2008). Tecnologia para a indústria: a história do Instituto Nacional de Tecnologia. Revista do Centro Edelstein de Pesquisas Sociais. Rio de Janeiro: Biblioteca Virtual de Ciências Humanas, pp. 4-136. Disponível: $\quad$ https://static.scielo.org/scielobooks/pmcfg/pdf/castro9788599662540.pdf. Acessado em: 20 nov. 2021.

CASTRO SANTOS, Luiz Antônio de (1985). O pensamento sanitarista na Primeira República: Uma ideologia de construção da nacionalidade. Revista de Ciências Sociais. Rio de Janeiro, vol. 28, n.2, pp.193-210.

CHIARADIA, Katia Nelsina Pereira (2008). Ao amigo Franckie, do seu Lobato: Estudo da correspondência entre Monteiro Lobato e Charles Frankie (1934-37) e sua presença em O Escândalo do Petróleo (1936) e O Poço do Visconde (1937). Dissertação (Mestrado em Teoria e História Literária). Universidade Estadual de Campinas, São Paulo.

CHIARADIA, Kátia (2016). Edição de textos fidedigna e anotada das cartas trocadas entre Monteiro Lobato e Charles Frankie (1934-1937): edição e estudo da correspondência entre Monteiro Lobato, Charles Frankie e alguns companheiros 
da Campanha Petrolífera, como Edson de Carvalho. Tese (Doutorado em Teoria e História Literária). Universidade Estadual de Campinas, São Paulo.

CPDOC/ FGV. Código de minas. Temático. Disponível em: <http://www.fgv.br/cpdoc/acervo/dicionarios/verbete-tematico/codigo-deminas>. Acesso em: 22 jan. 2020.

DALBEN, André et al. (2019). Criação do departamento de educação física do estado de São Paulo (1925-1932). Cadernos de Pesquisa. São Paulo, v. 49, n. 171, p. 264286, jan./mar.

ENGEL, Magali (2012). Os intelectuais e a Liga de Defesa Nacional: entre a eugenia e o sanitarismo? (RJ, 1916-1933). Intellèctus. Rio de Janeiro, vol. 11, pp. 1-30.

FERREIRA, A.C. (2000). A epopeia bandeirante: Letrados, Instituições, Invenção histórica (1870-1940). São Paulo: UNESP.

FUNDAÇÃO OSWALDO CRUZ (1992). Casa de Oswaldo Cruz. A ciência a caminho da roça: imagens das expedições científicas do Instituto Oswaldo Cruz ao interior do Brasil entre 1911 e 1913. Rio de Janeiro: Fiocruz.

GOMES, Ângela de Castro (2004). Escrita de si, escrita da História. Rio de Janeiro: FGV.

HOCHMAN, Gilberto (1993). Regulando os efeitos da interdependência: Sobre as relações entre saúde pública e construção do Estado (Brasil 1910-1930). Estudos Históricos. Rio de Janeiro, v. 6, n. 11, pp. 40-61.

HOCHMAN, Gilberto; LIMA, Nísia (2000). Pouca saúde, muita saúva, os males do Brasil são... Discurso médico-sanitário e interpretação do país. Ciência \& Saúde Coletiva. Rio de Janeiro, vol. 5, n. 2, pp. 313-332. Disponível em: https://www.scielo.br/j/csc/a/66wDTjPXBzZNxskLkXdsvJD/?format=pdf\&lang =pt. Acessado em: 20 nov. 2021.

HOCHMAN, Gilberto (2005). Reformas, instituições e políticas de saúde no Brasil (1930-1945). Educar. Editora UFPR. Curitiba, n. 25, pp. 127-141. Disponível em: https://www.scielo.br/j/er/a/YFprXwcGwr3jrnCXwRM8TGb/?lang=pt\&format= pdf. Acessado em: 20 nov. 2021.

IBAÑEZ, Nelson; RONCON, Olga; ALVES; Sofia Fabergé (2012). Homens modernos e um novo modelo para o Brasil: A correspondência entre Monteiro Lobato e Arthur Neiva (1918-42). Cadernos de História da Ciência. São Paulo: Instituto Butantan, vol. 8, pp. 231- 254, jul./dez.

LUCA, Tânia Regina de (1999). A Revista do Brasil: um diagnóstico para a (N)ação. São Paulo: UNESP.

LAURETTI, Patrícia (2016). Poder, literatura e petróleo. Pesquisadora analisa e comenta troca de correspondência entre Monteiro Lobato e engenheiro suíço radicado no país. Disponível em: https://www.unicamp.br/unicamp/ju/678/poder-literatura-epetroleo. Acessado em: 20 dez. 2019.

LEAL, Rhaiane das Graças Mendonça (2020). Nacionalismo militante: uma análise de correspondência de Monteiro Lobato e Arthur Neiva (1918-1942). Dissertação (Mestrado em História das Ciências e da Saúde). Casa de Oswaldo Cruz, Fundação Oswaldo Cruz, Rio de Janeiro.

LOVE, J. A (1982). A locomotiva: São Paulo na federação brasileira (1889-1937). Rio de Janeiro: Paz e Terra.

MICELI, Sergio (2001). Intelectuais e Classes Dirigentes no Brasil (1920-45). In: Intelectuais à Brasileira. São Paulo: Companhia das Letras, pp. 69-291.

NUNES, Cassiano (1981). O patriotismo difícil: a correspondência entre Monteiro Lobato e Artur Neiva. São Paulo: Copidart.

RIBEIRO, M.A.R. (1997). História, Ciência e Tecnologia - 70 anos do Instituto 
Biológico de São Paulo na defesa da agricultura. São Paulo: Instituto Biológico.

SÁ, Dominichi M. de. (2006). A ciência como profissão: médicos, bacharéis e cientistas no Brasil (1895-1935). Rio de Janeiro: Editora Fiocruz.

SÁ, Dominichi M. de (2009). A voz do Brasil: Miguel Pereira e o discurso sobre o imenso hospital. História, Ciências, Saúde - Manguinhos. Rio de Janeiro, v. 16, pp. 333348.

SIRINELLI, Jean-François (2003). Os intelectuais. In: RÉMOND, René (Org.). Por uma história política. Rio de Janeiro: FGV, pp. 231-269.

SILVA, André Felipe Cândido da (2006). Ciência nos cafezais: a campanha contra a broca do café em São Paulo (1924-1929). Dissertação (Mestrado em História das Ciências e da Saúde). Casa de Oswaldo Cruz. Fiocruz, Rio de Janeiro.

SILVA, André Felipe Cândido da (2011). A trajetória científica de Henrique da Rocha Lima e as relações Brasil-Alemanha (1901-1956). Tese (Doutorado em História das Ciências e da Saúde). Casa de Oswaldo Cruz. Fiocruz, Rio de Janeiro.

VISCARDI, Claúdia (2012). O teatro das oligarquias: uma revisão da "política do café com leite". Belo Horizonte: Fino Traço.

Artigo recebido em: 28 de agosto de 2021.

Artigo aprovado em: 22 de novembro de 2021.

DOI: 10.12957/intellectus.2021.61364 